\title{
Inovação didática no Ensino de Física em Nível Superior: o caso da disciplina Applied Physics 50 da Universidade de Harvard
}

Innovation in the teaching of introductory physics in higher education: the Applied Physics 50 course at Harvard University

\author{
Ives Araujo*1@, Tobias Espinosa ${ }^{2} @$ Kelly Miller $^{3}$, Eric Mazur $^{3}$ \\ ${ }^{1}$ Universidade Federal do Rio Grande do Sul, Instituto de Física, Porto Alegre, RS, Brasil. \\ ${ }^{2}$ Universidade Federal do Rio Grande, Instituto de Matemática, Estatística e Física, Santo Antônio da Patrulha, RS, Brasil. \\ ${ }^{3}$ Harvard University, School of Engineering and Applied Sciences, Cambridge, MA, United States.
}

Recebido em 15 de junho de 2021. Revisado em 15 de julho de 2021. Aceito em 16 de julho de 2021.

\begin{abstract}
No contexto das disciplinas introdutórias de Física em nível superior, o modelo de transmissão de informação em aulas expositivas continua predominante, apesar de seus resultados inferiores, em comparação a metodologias ativas de ensino. No presente artigo, apresentamos uma metodologia ativa vinculada à Aprendizagem Baseada em Projetos, criada no contexto da disciplina Applied Physics 50 (AP50) da Universidade de Harvard, explicitando seus princípios pedagógicos, técnicas e estratégias como estímulo para reflexão sobre possibilidades de reinvenção do ensino de Física em nível introdutório, consideradas as especificidades de cada contexto educacional.

Palavras-chave: Metodologias Ativas de Ensino, Aprendizagem Baseada em Projetos, Ensino de Física, Applied Physics 50 (AP50).
\end{abstract}

In the context of introductory physics courses in higher education, the transmission-based instructional model with lectures remains predominant, despite its inferior outcomes, compared to active teaching methods. In this paper, we present a team- and project-based teaching methodology, created in the context of the Applied Physics 50 (AP50), a course at Harvard University. We describe the pedagogical principles of AP50 as well as the teaching techniques and strategies as a stimulus for reflection on possibilities for reinventing the teaching of Physics at an introductory level, considering the specifics of each educational context.

Keywords: Active Teaching Methodologies, Project-Based Learning, Physics Education, Applied Physics 50 (AP50).

\section{Introdução}

Em 2020, a pandemia da COVID-19 transformou em desafio a realização das mais simples atividades humanas. $\mathrm{Na}$ área educacional, o encontro de professores e alunos sob o mesmo teto se tornou proibitivo ocasionando uma interrupção forçada das atividades de ensino ao redor do mundo. Até o momento, não se tem indícios de que interrupções similares não ocorrerão ciclicamente no futuro. Assim, indagações sobre como usar recursos tecnológicos digitais para viabilizar as aulas, onde disponíveis, e o que fazer quando não estão, passaram a ser frequentes.

Em contextos onde o método tradicional de ensino é predominante, as atenções se voltam a como dar continuidade à transmissão de informações do professor para os alunos, agora de forma remota, e como viabilizar que os estudantes realizem e entreguem as listas de exercícios e problemas à distância. Em outras palavras, buscam-se meios para se continuar a realizar o mesmo

\footnotetext{
*Endereço de correspondência: ives@if.ufrgs.br
}

tipo de atividade e da forma que mais se assemelhe ao que vinha sendo feito.

Esse é um cenário comum em disciplinas de Ciência, Tecnologia, Engenharia e Matemática (STEM, na abreviatura em inglês), incluindo disciplinas introdutórias de Física em nível superior. A perpetuação do método tradicional de ensino não se sustenta pelos resultados de aprendizagem que promove [1. Esse resultado é apontado por Freeman et al. [2] que o fazem a partir de uma meta-análise de 225 estudos que compararam o desempenho em testes ou taxas de reprovação de estudantes em cursos STEM. O trabalho aponta que, comparados com o ensino tradicional, pautado por aulas expositivas, melhores resultados de aprendizagem são alcançados quando as aulas são ministradas com métodos ativos, caracterizados por centrarem o ensino nos alunos e no processo de construção de conhecimento por parte deles [1]. Com métodos ativos, o desempenho dos discentes nos testes foi em média cerca de 0,47 desvios-padrão maior do que quando assistiam aulas tradicionais. A taxa de reprovação, por sua vez, foi 
1,5 vezes maior para os estudantes que tiveram aulas tradicionais.

Em muitas instituições, é possível que a adoção continuada da metodologia tradicional de ensino, mesmo com resultados de aprendizagem pouco satisfatórios, se deva, em parte, à grande familiaridade do corpo docente com ela e à possibilidade de otimização de problemas logísticos de alocação de tempo e distribuição de alunos e professores no espaço físico disponível. Evidentemente tais aspectos são importantes e precisam ser endereçados, mas é fundamental ter em mente o peso que estão recebendo na definição da prática docente. É preciso cuidar para que elementos burocráticos e/ou circunstanciais não coloquem em risco a própria razão de ser das atividades de ensino. Depois de naturalizados, tais elementos podem continuar influenciando o ensino, mesmo se as razões pelas quais foram considerados em primeiro lugar não se fizerem mais presentes. Assim, ainda que ocorresse uma mudança radical das condições que originalmente sustentavam a adoção de metodologias essencialmente expositivas no passado, elas continuariam onipresentes nas salas de aula. É o caso, por exemplo, da ação docente de transpor informações disponíveis em livros-texto (ou similares) para a lousa ou slides, de modo que os alunos possam registrar em seus cadernos, mesmo quando todos possuem acesso direto às informações. Tal prática se justifica, ou se justificava, em contextos com obstáculos para o acesso ou reprodução de informações, mas dificilmente esse é o caso na maior parte das instituições de ensino superior em que continua sendo executada.

A concepção de metodologia tradicional de ensino que aqui adotamos vai ao encontro da caracterização realizada por pensadores do movimento escolanovista, como John Dewey, para definirem, por oposição, seus princípios de ensino [3]. O termo tradicional se refere à forma dominante que o ensino era realizado no final do século XIX, e que ainda hoje, com algumas variações, se faz presente em boa parte das instituições de ensino. Suas características mais marcantes são: instrução dirigida a turmas de alunos; transmissão de conteúdos padronizados em aulas expositivas, centradas no docente; ênfase na realização de exercícios e solução de problemas de livro-texto, como atividade central para aprendizagem discente; fomento ao comportamento passivo, considerando interações entre os discentes como distrações a serem evitadas; e foco na memorização avaliada por provas escritas e testes padronizados.

Ao olhar para além das tarefas e técnicas didáticas empregadas no ensino tradicional, poderemos perceber o vínculo com princípios pedagógicos implícitos que, se expostos à luz do dia, seriam de difícil sustentação em pleno século XXI, como a ideia de que a aprendizagem é alcançada quando o estudante é capaz de reproduzir aquilo que lhe foi ensinado, mesmo que de forma mecânica; ou que a mente dos alunos é uma "tábula rasa" na qual o conhecimento exposto em aula será registrado.
Essa caracterização e enunciação de princípios pode soar caricata aos docentes, e gerar resistência em enxergar nela o exercício de suas práticas, pois percebem variações de ordem técnica no que hoje é realizado. Contudo, um ponto central permanece: a transmissão de conhecimentos via aulas expositivas, mesmo quando existem alternativas mais adequadas à disposição. Não raro, se recorre a ele para enunciar, de forma demasiadamente simplista, a própria definição do que é ser professor: "aquele que dá aulas".

Voltando à discussão inicial, não é difícil perceber que existe o sério risco de que a viabilização do ensino, quando encontros presenciais não se fazem possíveis, se traduza na busca por meras soluções técnicas para continuar a empregar a metodologia tradicional de ensino. E isso pode ter consequências graves e indesejáveis a médio prazo. Em um primeiro momento, o uso das tecnologias disponíveis, pensadas para outros contextos, pode moldar a forma como as interações humanas acontecem, trazendo "por contrabando" valores diferentes ao que se busca em instituições educacionais. Entretanto, o principal problema está na aceleração na direção errada do desenvolvimento de tecnologias educacionais voltadas para "otimizar" o processo de ensino. É comum empresas que desenvolvem software educacional estudarem o que fazem tipicamente os professores e tentarem reproduzir o mesmo de forma digital. Se o que os professores fazem é transmitir informações em aulas expositivas a uma classe de alunos, aplicar e corrigir tarefas e exames, por que não otimizar o processo? Por que não contratar uma equipe que conte com os melhores palestrantes e produzir materiais de qualidade hollywoodiana para ensino em massa? Se poderia dispensar performances individuais docentes em cada sala de aula e ainda, empregar recursos de inteligência artificial para corrigir tarefas e dar feedback personalizado aos alunos. Não estamos diante de caso similar ao ocorrido com o surgimento e evolução das vitrolas? Elas permitiram a reprodução de canções dos melhores artistas a qualquer momento, dispensando a contratação de músicos para cada evento de celebração que se quisesse fazer. Não se passará o mesmo com a evolução dos recursos digitais e os professores? Seguindo essa lógica, em breve gestores começarão a ver cada vez mais oportunidades de diminuição de custos com a formação e contratação de professores, com mais um caso onde a máquina substituiu o homem.

No presente artigo, nosso objetivo é contribuir para a reflexão sobre alternativas que possam enriquecer a prática docente e apontem em outra direção: a do uso de recursos tecnológicos para viabilizar metodologias de ensino não perfeitas, mas perfectíveis, alinhadas a princípios pedagógicos explícitos e coerentes. Para isso, é preciso ampliar a visão do que se pode almejar e promover com atividades de ensino, consideradas sempre as condições de exequibilidade em cada contexto, sem a pretensão da reprodução de receitas prontas. 
Assim, na seção seguinte, descrevemos em detalhe uma proposta inovadora de ensino, no contexto das disciplinas introdutórias de Física, tanto em sua forma presencial quanto em sua adaptação para o ensino remoto, explicitando os princípios pedagógicos que a orientam. A proposta é materializada na disciplina Applied Physics 50 (AP50), criada pelo professor Eric Mazur (terceiro autor do presente artigo) e promovida pela Escola de Engenharia e Ciências Aplicadas (School of Engineering and Applied Sciences) da Universidade de Harvard. A AP50 é orientada por princípios pedagógicos que sustentam, por exemplo, que os alunos podem aprender uns com os outros, que o erro é um fator importante para a aprendizagem e que o estudante precisa ter autonomia e se envolver em atividades que tenham propósito para ele. Tem como objetivos principais, além do domínio do conteúdo de Física e suas aplicações em situações reais, o desenvolvimento de habilidades de aprendizagem autodirigida, trabalho em equipe e profissionalismo. $\mathrm{Na}$ prática, os alunos trabalham em equipes, por um longo período, em projetos de investigação e produção de artefatos, guiados pela busca por soluções a problemas do mundo real. As demais atividades, que ocorrem em classe e extraclasse, todas com engajamento ativo e colaborativo dos estudantes, visam preparar as equipes progressivamente para resolverem os problemas que surgem na concretização dos projetos. Em termos de metodologia de ensino, a AP50 é fundamentada na Aprendizagem Baseada em Projetos [4] e na Aprendizagem Baseada em Equipes [5], podendo ainda ser caracterizada como um modelo de Sala de Aula Invertida 6. Mais do que apresentar técnicas e recursos tecnológicos que podem auxiliar à prática docente, almejamos iluminar diferentes concepções pedagógicas e objetivos para o ensino de disciplinas introdutórias de física.

Cabe destacar que a metodologia de ensino utilizada nessa disciplina está em evolução e que, de certo modo, apresentamos uma "fotografia" de uma inovação didática em movimento. É provável que aspectos particulares e circunstanciais se alterem conforme as experiências pedagógicas em ensino remoto informem à prática docente.

Nas considerações finais, reforçamos nossos votos de que a partir de uma tragédia humanitária, iniciada por uma pandemia, pode haver a oportunidade de se repensar o ensino que temos coletivamente oferecido.

\section{Proposta de Inovação Didática para o Ensino de Física}

As palavras "métodos", "metodologias", "ensino" e "aprendizagem" têm sido combinadas com a palavra "ativa" (e seus derivados) para designar abordagens educacionais afins sob os termos: "Aprendizagem ativa"; "métodos/metodologias ativos(as) de aprendizagem"; e "métodos/metodologias ativos(as) de ensino". Essas abordagens não são novas, mas frequentemente reinventadas em função de recursos tecnológicos antes indisponíveis ou não acessíveis. É possível encontrar na literatura trabalhos conectando suas origens: à antiguidade com Sócrates [7] aos projetos nas escolas de arquitetura da Europa em 1590 [8]; e de modo mais frequente, ao movimento "Escola Nova" no final do século XIX e início do século XX, em particular aos trabalhos de Dewey, Kilpatrick e Decroly [9 13].

Nas definições dos referidos termos também é possível delinear um núcleo comum: oposição à ideia de centrar o ensino na transmissão de informações por parte do professor. O centro deve estar no engajamento dos estudantes em atividades que lhes permitam construir conhecimentos e desenvolver habilidades. O processo de ensino-aprendizagem, nessa perspectiva, se orienta a partir do planejamento e implementação de situações que ofereçam oportunidades para que isso aconteça, com maior ou menor ajuda do professor. Se enquadram nessa linha, por exemplo, metodologias de aprendizagem baseadas em problemas/projetos/investigação; de inversão da sala de aula (Flipped Classroom); e métodos como Peer Instruction, Just-in-Time Teaching e Team-Based Learning.

Outros princípios pedagógicos podem ser agregados ao núcleo comum para gerar ou sustentar diferentes tipos de metodologias ativas de ensino. Explicitamos ao longo desta seção aqueles com maior protagonismo na proposta didática analisada (AP50) e como foram considerados. Nosso objetivo, como já mencionado, é expor formas alternativas ao método tradicional de ensino no contexto de Física Geral. Cabe ressaltar que isso não se trata da negação da importância de outros princípios, aqui ausentes ou implícitos, mas sim de um recorte para o procedimento de análise.

\subsection{Applied Physics 50 - AP50}

Na Universidade de Harvard (EUA), o Quarto autor deste artigo tem dedicado esforços consistentes nas últimas décadas para promover inovações didáticas em disciplinas científicas nas áreas de Ciências e Engenharia. Um exemplo de suas ações está na criação, aplicação e divulgação do método de ensino Peer Instruction (ou Instrução pelos Colegas), que tem sido um dos mais implementados em instituições de ensino superior que buscam alternativas às aulas essencialmente expositivas nas referidas áreas [14-16]. Tal método tem como princípio fundamental que os estudantes podem ensinar e aprender uns com os outros na medida que defendem e discutem suas próprias respostas a questões conceituais apresentadas pelo professor.

$\mathrm{Na}$ busca por ampliar ainda mais o engajamento discente em atividades de ensino, primando pelo domínio do conteúdo; habilidades de trabalho em equipe; aprendizagem autodirigida; e profissionalismo; foi construída uma proposta didática na forma de disciplina: a Applied Physics 50 (AP50) - Physics as a Foundation for Science and Engineering. Trata-se de um modelo de disciplina de Física introdutória da Escola de Engenharia 
e Ciências Aplicadas (School of Engineering and Applied Sciences) da Universidade de Harvard (EUA), voltado, principalmente, a estudantes de engenharia. Esse modelo é empregado em duas disciplinas semestrais: a AP50a, focada em tópicos de Mecânica Clássica e Ondulatória; e a AP50b, que aborda temas de Eletromagnetismo e Óptica. Cada disciplina é ofertada uma vez por ano, em sequência. As turmas contam com no máximo 75 alunos, oito monitores e até dois professores. Por uma questão de simplicidade, nos referimos deste ponto em diante apenas "a disciplina AP50", no singular.

Em seu formato presencial, costumam ocorrer três encontros semanais de duas horas cada, sendo um deles destinado à construção de projetos em equipes. A disciplina foi ofertada pela primeira vez em 2012 e vem passando por aprimoramentos desde então. A última modificação de destaque ocorreu no primeiro semestre de 2020, em função da pandemia da COVID-19. Ao apresentarmos o detalhamento da proposta, indicaremos como as atividades vinham sendo implementadas na modalidade presencial e como foram adaptadas para a modalidade a distância.

Em termos de metodologia de ensino, a AP50 fundamenta-se na Aprendizagem Baseada em Projetos (ABP) 4] e na Aprendizagem Baseada em Equipes (ABE) [5], e pode ser caracterizada como um modelo de Sala de Aula Invertida [6].

Em propostas de ABP, é comum os alunos trabalharem por um longo período em projetos de investigação e produção de artefatos, orientados pelo professor, a partir de problemas do mundo real que tenham sentido para eles. A ideia é oportunizar aos estudantes a construção de conhecimentos e habilidades específicas conforme realizam as atividades de estudo, pesquisa e aplicação do que aprenderam para resolver os problemas presentes na concretização dos projetos.

$\mathrm{Na} \mathrm{ABE}$, os estudantes são organizados, pelo professor, em pequenos grupos que ficam fixos por um período de pelo menos um mês. A interação constante entre os membros do grupo em todos os aspectos da disciplina, incluindo nas avaliações, possibilita que sejam transformados em equipes de aprendizagem, nas quais, segundo Fink (2004), os alunos apresentam comprometimento individual para o bem do grupo e confiança entre os membros. Na AP50, os estudantes trabalham em três projetos por semestre, realizados em equipes, de quatro a cinco estudantes, que mudam a cada projeto, assim como o respectivo "Mentor da Equipe". Esse papel é desempenhado por um monitor para auxiliar em qualquer aspecto que se faça relevante para o bom andamento dos trabalhos. A formação das equipes não é de livre escolha dos próprios alunos; é realizada pelo professor que busca, ao criá-las, maximizar a diversidade dos participantes em relação a critérios como conhecimento prévio de física, gênero, curso, ano do curso e experiência prévia em atividades experimentais. As informações não disponíveis no histórico dos alunos são obtidas com o uso de um questionário de perfil e testes diagnósticos como o FCI [17] e o BEMA [18, respondidos de forma online na primeira semana da disciplina.

O modelo de Sala de Aula Invertida, comum a diferentes metodologias ativas de ensino, preconiza a inversão de ações da prática tradicional de ensino: o primeiro contato do aluno com o conteúdo, que usualmente é feito na presença do professor por meio de exposições, passa a ser realizado extraclasse, por intermédio de algum material previamente selecionado pelo professor (e.g., vídeo e texto); e o engajamento ativo dos estudantes em atividades de aplicação dos conceitos aprendidos, que tradicionalmente acontece fora do período de aula, passa a ocorrer no momento destinado à aula, com a colaboração dos colegas e mediação do docente.

A AP50, baseada em princípios pedagógicos e técnicas presentes nas metodologias descritas, é composta por atividades assíncronas e síncronas, divididas em três momentos: antes da aula, durante da aula e ao longo do semestre. Antes das aulas, usualmente, ocorre a atividade assíncrona de preparação prévia, na qual os estudantes leem colaborativamente algumas páginas do livro-texto adotado Principles 83 Practices of Physics [19]. O termo síncrono/assíncrono está relacionado com a participação ou não de alunos e professores ao mesmo tempo em determinado ambiente, presencial ou virtual, que lhes permita interagir.

De forma síncrona, durante as aulas, os alunos se envolvem em uma série de atividades com suas equipes que vão, progressivamente, possibilitando o domínio dos conceitos. Essas atividades, discutidas na subseção 2.1.2. podem ser classificadas em três tipos: atividades de entendimento dos conceitos (Peer Instruction e Tutoriais), de aplicação dos conceitos (Atividades de Estimativa e Atividades de Delineamento Experimental) e de avaliação da aprendizagem (Conjuntos de Problemas Reflexões e Readiness Assurance Activity $\}^{1}$.

Ao longo do semestre os estudantes se envolvem, em equipes, em atividades de transposição dos conhecimentos para o contexto real. Isso ocorre por meio do desenvolvimento de projetos, os quais são apresentados em feiras com avaliadores externos à disciplina. Um exemplo de como essas atividades se distribuem no tempo é exposto na Figura 1 A sequência de atividades extraclasse se repete para cada nova unidade do livrotexto (composta por cerca de três capítulos) e leva entre duas e três semanas para ser completada.

Na sequência, apresentamos cada uma das atividades de acordo com suas temporalidades, indicando os princípios pedagógicos subjacentes e maneiras de viabilizá-las em aulas presenciais e/ou remotas.

\footnotetext{
1 Optamos por utilizar o termo em inglês "Readiness Assurance Activity" porque traduções literais do termo, como "Atividade de Garantia de Preparação", parecem fazer pouco sentido em português.
} 


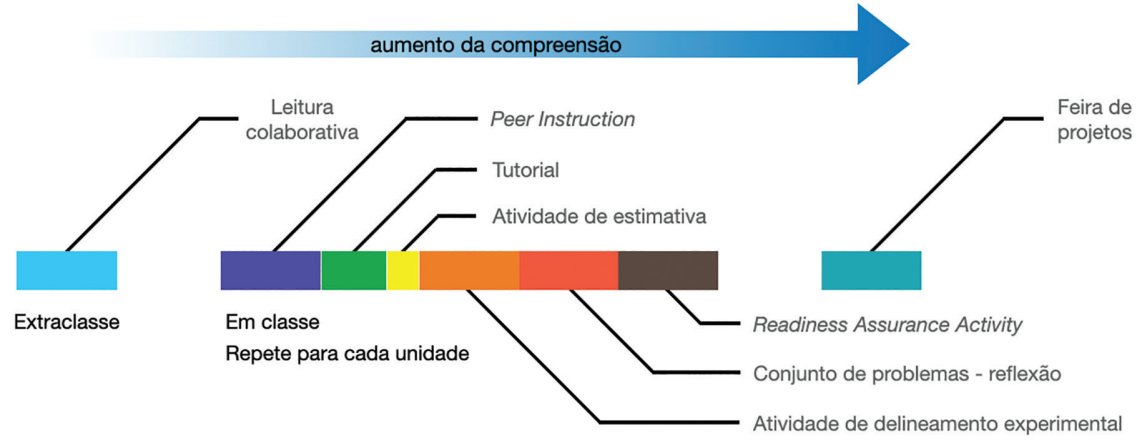

Figura 1: Sequência de atividades da AP50. O comprimento das barras é uma representação (sem escala) do tempo alocado para cada atividade.

\subsubsection{Antes das aulas}

Na AP50, os estudantes, de modo assíncrono, tomam contato com o conteúdo a ser aprendido por meio de atividades de preparação prévia aos encontros síncronos, como de praxe em abordagens de ensino alinhadas com o modelo Sala de Aula Invertida. Além disso, são fornecidos conjuntos de problemas (Problem Sets pre-class) para que o estudante tente resolvê-los individualmente. Em uma segunda fase, em aula, o aluno deverá refletir sobre suas próprias soluções em discussões com seus colegas de equipe (Problem Set Reflection in-class). Parte-se do princípio de que o tempo em aula é melhor aproveitado com atividades que os auxiliem a aprofundar a compreensão dos conceitos, com a colaboração do professor e dos colegas. A primeira exposição dos discentes às informações a serem discutidas é realizada extraclasse, não em aulas expositivas (abolidas na disciplina).

As atividades preparatórias envolvem o estudo de princípios físicos necessários para o desenvolvimento dos projetos. Isso é feito a partir da leitura de seções relevantes do livro-texto, de acordo com o calendário das aulas; expressão de dúvidas e comentários sobre trechos da leitura; e/ou resposta a dúvidas ou comentários feitos pelos colegas em um sistema colaborativo de anotações em documentos digitais chamado Perusall $\mathrm{2}^{2}$ Nesse programa, o professor pode enviar seus próprios materiais e uma versão em PDF ficará disponível para seus alunos estudarem. Durante a leitura, cada aluno, de forma assíncrona, pode destacar trechos do texto e inserir suas anotações, ao mesmo tempo em que pode visualizar e responder anotações feitas pelos colegas. Além de oferecer aos discentes a oportunidade de obter respostas às suas próprias questões, e ajudar os colegas com as dúvidas deles, o registro das anotações fornece subsídios ao professor para que possa melhor preparar as atividades de ensino síncronas. Por exemplo, no encontro com a turma, o professor pode iniciar o diálogo

2 O Perusall (https://perusall.com) é um software gratuito, utilizado para estudo prévio, que permite a colaboração entre estudantes por meio de marcações e anotações em arquivos no formato PDF compartilhados pelo professor. a partir dos pontos que mais suscitaram dificuldades de compreensão usando, sem identificar, as próprias perguntas dos alunos. Na Figura 2 apresentamos um exemplo do ambiente virtual e da dinâmica de leitura colaborativa no software.

O aplicativo permite a separação automática ou manual dos estudantes em grupos para a leitura de modo que o texto não fique sobrecarregado com muitas anotações para turmas grandes. De forma independente, as anotações também podem ser ocultadas durante a leitura se o estudante assim o desejar. Os comentários são avaliados com base em critérios de qualidade (nível de reflexão), pontualidade, quantidade e distribuição ao longo do texto $3^{3}$ Tal avaliação pode ser feita automaticamente pelo software e/ou de forma manual pelo professor. Recentemente, a possibilidade da apresentação dos materiais para preparação prévia na forma de vídeos foi inserida na ferramenta, contando também com dinâmica similar a da anotação colaborativa dos materiais escritos para esse tipo de mídia.

Cabe destacar que a preparação prévia colaborativa é um tipo de atividade que não se restringe ao software Perusall. Apesar de o aplicativo facilitar bastante a viabilização das atividades, com recursos especialmente pensados para esse fim, o uso de outras ferramentas é possível.

A leitura extraclasse, realizada de forma colaborativa, se fundamenta no princípio pedagógico - subjacente a todas as atividades da AP50 - de que os alunos podem aprender uns com os outros. Nessa atividade, o aluno está no centro do processo educativo, tanto do ponto de vista das ações indicadas para seu próprio engajamento no estudo do material, quanto por parte do professor que prepara as atividades síncronas sob medida para a turma.

Quanto à resolução de problemas de forma individual antes das aulas, a ideia principal é que o estudante tenha oportunidade de perceber suas próprias dificuldades e

\footnotetext{
3 O protocolo original de avaliação das anotações no ambiente virtual de estudo colaborativo (Perusall) pode ser acessado em: https://if.ufrgs.br/ ives/harvard/ap50/annex1.pdf
} 


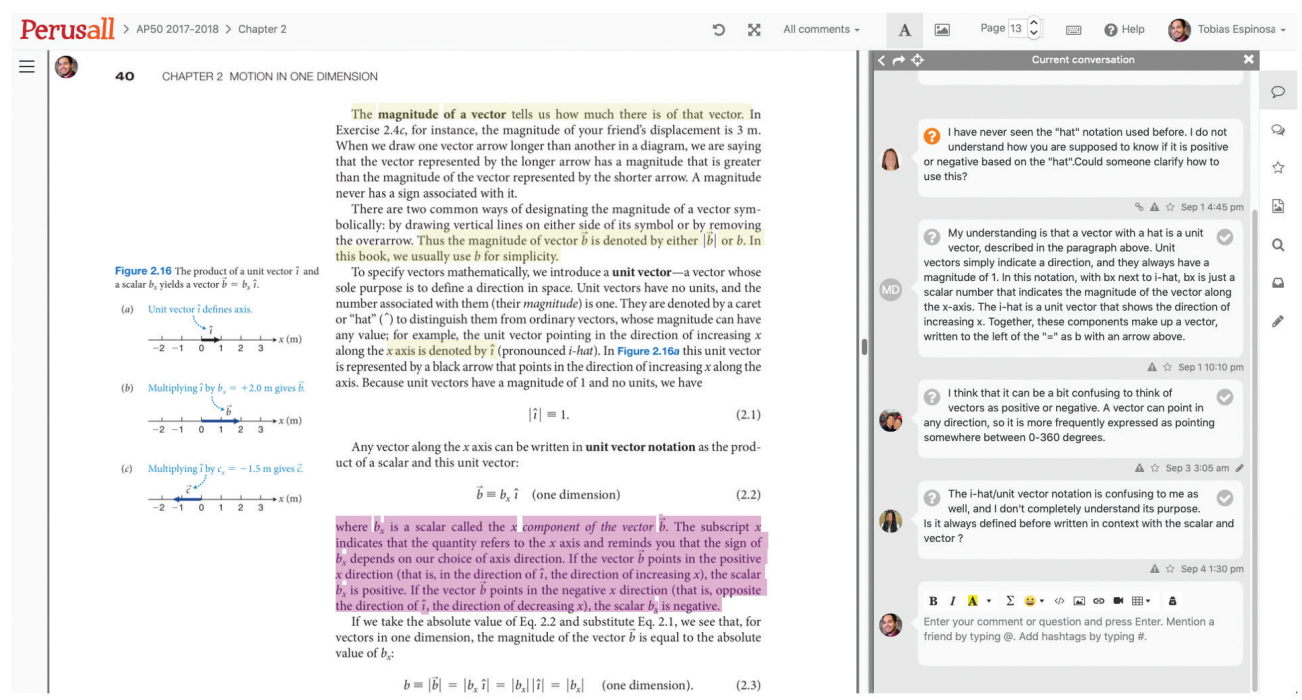

Figura 2: Exemplo do material resultante de uma discussão entre os alunos na plataforma colaborativa para anotações em documentos digitais.

melhor avaliar o que está conseguindo realizar sozinho. A avaliação por parte do professor é feita a partir do esforço demonstrado na resolução dos problemas e na precisão da autoavaliação realizada pelos estudantes (vide seção 2.1.4) $]^{4}$ Como já mencionado, esta etapa individual extraclasse se conecta com uma etapa coletiva em aula, de forma complementar, para o desenvolvimento da habilidade de resolução de problemas por parte dos estudantes.

Em aulas tradicionais, a maior parte do tempo é destinada à exposição do conteúdo pelo docente, e fica a cargo do discente aprofundar sua aprendizagem, sozinho, em ações fora da aula. Ao estudar o material previamente, o aluno pode aprender em seu próprio ritmo e se responsabilizar pela própria aprendizagem. Além disso, ao expressar suas dúvidas e argumentos, pode perceber lacunas na própria compreensão do conteúdo estudado, e procurar o auxílio necessário.

Espera-se que nas atividades preparatórias os estudantes construam conhecimento suficiente para poderem participar das atividades em aula de forma substantiva e que se tornem corresponsáveis pela própria aprendizagem e pela dos colegas.

A preparação prévia colaborativa já inclui o uso de ferramenta digital para a realização do trabalho à distância e nenhuma adaptação se faz necessária para viabilização da AP50 em forma remota. Já a resolução de problemas extraclasse, usualmente feita de forma manuscrita, e cujas páginas em papel eram usadas para os alunos apresentarem suas soluções em aula, precisará ser digitalizada para que possam ser melhor discutidas nos encontros síncronos virtuais. Uma solução simples é

$\overline{4} \mathrm{O}$ protocolo original de avaliação das soluções dos problemas pode ser acessado em: https://if.ufrgs.br/ ives/harvard/ap50/a nnex2.pdf tirar fotos das páginas em papel com um aparelho celular e gerar um arquivo eletrônico.

\subsubsection{Durante a aula}

Conforme já indicado, a adoção de um modelo de Sala de Aula Invertida para o ensino permite que o tempo em classe, usualmente investido na transmissão de informações do professor para os alunos, seja alocado para atividades que favoreçam um aprofundamento na compreensão dos conteúdos estudados. Na AP50, o objetivo principal das atividades de ensino nos encontros síncronos é auxiliar os estudantes a construírem um entendimento sólido sobre os princípios físicos necessários para o desenvolvimento dos projetos. Para isso, são propostas atividades que enfatizam a:

- compreensão conceitual dos conteúdos de física com o emprego do método Peer Instruction (PI) e de um conjunto de tutoriais sobre conteúdos introdutórios de física (Tutorials). O primeiro foca no entendimento dos conceitos-chave dos conteúdos em estudo, e o segundo trabalha os erros e confusões mais frequentes relacionados a cada conceito.

- aplicação de conceitos em estimativas de grandezas (Estimation Activity) e em delineamentos experimentais (Experimental Design Activity) que incluem o planejamento de medidas, coleta e análise de dados, e uso de simulações computacionais;

- avaliação formativa da aprendizagem com a discussão e reflexão coletiva sobre soluções de problemas, resolvidos individualmente extraclasse (Problem Set Reflection); e com o uso de testes (Readiness Assurance Activity) que permitam avaliar se objetivos específicos de aprendizagem 


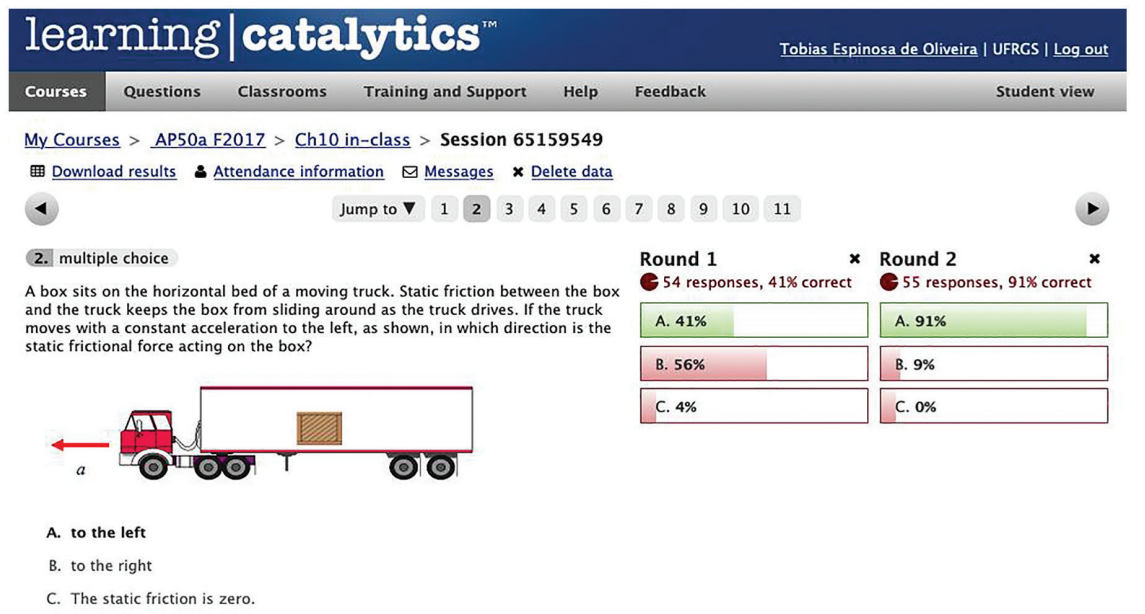

Figura 3: Exemplo de questão conceitual no Learning Catalytics, vista pelo professor durante a segunda votação dos alunos.

(associados aos conteúdos), bem como a melhoria da habilidade de resolver problemas, foram alcançados.

$\mathrm{Na}$ sequência, descrevemos os métodos de ensino associados a cada um desses eixos.

\subsubsection{Peer Instruction}

Em essência, o método Peer Instruction busca favorecer a compreensão de conceitos-chave do conteúdo por meio da argumentação e de discussões entre os alunos. A partir da resposta dada a um teste conceitual apresentado pelo professor, os estudantes precisam sustentar suas próprias respostas, na tentativa de convencerem colegas que tenham respondido de modo diferente.

Parte-se do princípio pedagógico de que a ação de ensinar e/ou aprender com um colega pode complementar e expandir o que se pode aprender sozinho ou apenas auxiliado pelo professor. Além disso, a discussão entre os discentes estimula a capacidade de questionar, ouvir e identificar múltiplas abordagens e pontos de vista.

$\mathrm{Na}$ forma usual do PI, os alunos recebem tarefas preparatórias às aulas e, em sala, a aplicação do método se inicia com uma breve exposição oral por parte do professor sobre algum conceito específico dos conteúdos previamente estudados. Em seguida, o docente apresenta à turma um teste conceitual (Conceptest) que busca avaliar a compreensão alcançada pelos estudantes. Nesse momento, eles são instruídos a responder o teste individualmente, sem conversar com os colegas, e formular um raciocínio que lhes permita convencer quem não tenha respondido da mesma forma. Após alguns minutos, o professor inicia o registro das respostas por meio de um sistema de votação (e.g., flaschcards, clickers, plickers etc.). Se o percentual de acertos estiver no intervalo $30 \%-70 \%$, os estudantes são orientados a conversar com os colegas, buscando quem tenha respostas diferentes, e a tentar convencer uns aos outros, usando as justificadas que formularam ao responder individualmente. Depois de alguns minutos, uma nova votação é realizada e, a partir da nova distribuição de respostas, o professor decide se parte para um novo tópico ou retoma o conteúdo com uma nova questão. Caso a distribuição de respostas na primeira votação seja menor do que $30 \%$, o docente realiza uma nova explicação - utilizando, por exemplo, outros recursos para melhor explicar os conceitos - e propõe um novo teste conceitual sobre o mesmo conceito. Quando a quantidade de acertos na primeira votação fica acima de $70 \%$, o professor pode optar por discutir diretamente com toda a turma a questão [14, 15].

A atividade não é pontuada em função de acertos e erros. A participação individual no PI é avaliada pelos demais membros da equipe e pelo professor como um fator na composição do escore associado à dimensão Profissionalismo (vide seção 2.1.4). As atividades expostas em seguida (Tutoriais, Atividades de Estimativa e Atividades de Delineamento Experimental; seções 2.1.2.2. 2.1.2.3 e 2.1.2.4 respectivamente) seguem o mesmo critério avaliativo 5

Tanto na versão presencial quanto na versão online da AP50, o sistema de votação utilizado é o software Learning Catalytics.6 ${ }^{6}$ o programa dispõe de uma interface para o professor (gerenciamento) e outra para os alunos (votação) e o acesso se dá via web browser em dispositivos conectados à internet. Esse programa permite que o professor crie ou selecione questões disponíveis em um banco de dados e as apresente como testes conceituais para a turma. Ao iniciar o processo de votação, as respostas dos alunos são monitoradas em tempo real. Na Figura 3 apresentamos um exemplo de

\footnotetext{
${ }^{5} \mathrm{O}$ protocolo original de avaliação referente à dimensão profissionalismo pode ser acessado em: https://if.ufrgs.br/ ives/harvard/ ap50/annex3.pdf

- O Learning Catalytics (https://learningcatalytics.com) é um software que permite o engajamento dos estudantes em resposta a questões propostas pelo docente. A ferramenta também possibilita o trabalho colaborativo entre os alunos.
} 
questão conceitual na tela do Learning Catalytics, vista pelo professor durante a segunda votação dos alunos. Ao longo do semestre, o professor conduz cerca de oito sessões de Peer Instruction, com aproximadamente 1h30min cada. Em uma sessão, os alunos respondem em torno de 10 questões.

Para viabilizar o encontro virtual do professor com a turma, na versão online da AP50 é utilizado um aplicativo de webconferência, o Zoom.7 Além de permitir a interação entre os participantes nos encontros síncronos, com recursos de áudio, vídeo, compartilhamento de tela, entre outros, o programa possibilita a formação de salas de apoios nas quais os membros de cada equipe são reunidos para discutir suas respostas para os testes conceituais. A distribuição dos alunos nas salas de apoio, ou a reunião de toda a turma em uma mesma sala virtual, é controlada pelo professor. Tanto ele quanto os mentores das equipes podem visitar as salas enquanto as discussões ocorrem.

\subsubsection{Tutoriais}

Desde que foi lançado em 2002 os Tutorials in Introductory Physics [20], aqui referidos apenas como Tutoriais, têm sido amplamente utilizados nos EUA como materiais suplementares em aulas de Física no ensino superior. Os Tutorais são compostos por um conjunto de problemas especialmente projetados para eliciar, confrontar e resolver as principais dificuldades conceituais comumente apresentadas pelos alunos no estudo de conteúdos de Física. Os materiais foram delineados para serem trabalhados em pequenos grupos, e com o auxílio do professor (e/ou monitores), em determinados momentos (checkpoints). Sua construção é baseada nos resultados obtidos em mais de 20 anos de pesquisa sobre o tema realizada pelos autores, membros do Grupo de Pesquisa em Ensino de Física da Universidade de Washington (EUA).

O princípio básico que orienta o trabalho com os Tutoriais é que os alunos devem estar cognitivamente ativos para alcançar um entendimento funcional dos conteúdos ensinados. Isso implica em desenvolvimento de habilidades de raciocínio que lhes permitam aplicar conceitos e princípios relevantes para resolver situações não explicitamente estudadas. O engajamento cognitivo se dá ao tentarem responder questões especialmente construídas para: eliciar concepções alternativas (misconceptions), em um primeiro momento; reconhecer e confrontar suas respostas anteriores com aquelas cientificamente aceitas, na sequência; e, por último, resolver tais conflitos. Assim como no Peer Instruction, a implementação dos Tutoriais também assume como princípio que um aluno pode aprender com o outro, e que a discussão entre colegas fomenta a capacidade de questionar, ouvir e identificar

\footnotetext{
7 O Zoom (https://zoom.us) é uma ferramenta de webconferência que possibilita, dentre outros aspectos, a separação de grupos de pessoas em salas de apoio.
}

diferentes pontos de vista sobre um mesmo assunto.

$\mathrm{Na}$ AP50, em sua modalidade presencial, as equipes trabalham cerca de uma hora na resolução das questões de um Tutorial, utilizando quadros brancos móveis para facilitar a comunicação de ideias. Ao término da atividade, as equipes verificam suas respostas com o mentor da equipe ou o professor. Na versão online, as sessões de trabalho com os Tutoriais se dão de forma síncrona com as equipes e seus respectivos mentores em salas de webconferência, uma por equipe, no aplicativo Zoom. As questões são apresentadas em uma plataforma online chamada Desmo 8 que permite ao professor organizá-las em páginas separadas e acompanhar quais estudantes estão respondendo o quê, a qualquer momento. Cada estudante é incentivado primeiro a responder às questões, de forma individual, em seu próprio ritmo. A ideia é que todos consigam resolver toda a lista de questões até o final da sessão, mas alguns podem responder mais rápido do que outros. Ao terminar de responder uma questão, o estudante pode passar imediatamente para a próxima. Entre subgrupos de questões são inseridas páginas do tipo checkpoint instruindo os alunos a discutirem suas respostas com os colegas e com o mentor da equipe, quando todos os membros tiverem alcançado essa página. Para ilustrar, imagine que a sessão contenha um total de 12 questões, uma por página, a serem respondidas em $1 \mathrm{~h}$. A cada quatro questões é colocada uma página de verificação (checkpoint). O mentor acompanha pelo sistema quais questões estão sendo respondidas pelos membros da equipe e avisa na sala de webconferência quando todos atingem a quinta página. Nesse momento, os estudantes que estiverem respondendo questões além da página cinco param suas atividades e toda equipe se concentra na discussão das respostas dadas por cada um para o primeiro subgrupo de quatro questões. Após a discussão, mediada pelo mentor, o processo se repete até que todas as questões tenham sido completadas e discutidas. A Figura 4 mostra uma tela do aplicativo, onde é possível observar as respostas fornecidas pelos alunos para determinada questão e também o número de alunos que estão respondendo cada questão (canto inferior direito de cada página na barra superior).

\subsubsection{Atividades de estimativa}

No ensino de Física, o desenvolvimento de habilidades em fazer estimativas e determinar a ordem de magnitude de grandezas não pode ser enfatizado o suficiente. Para alcançar tal fim, na proposta original da AP50 são realizadas competições entre equipes voltadas para a solução de problemas abertos (Fermi problems). Por exemplo: "Estime o número de prótons em uma garrafa de 1 L de refrigerante", ou ainda, "Estime, em newtons, a

8 O Desmos (https://www.desmos.com) é um ambiente virtual de aprendizagem com ênfase em Matemática que permite, dentre outros aspectos, que o professor insira atividades e acompanhe o andamento de cada estudante de forma síncrona. 


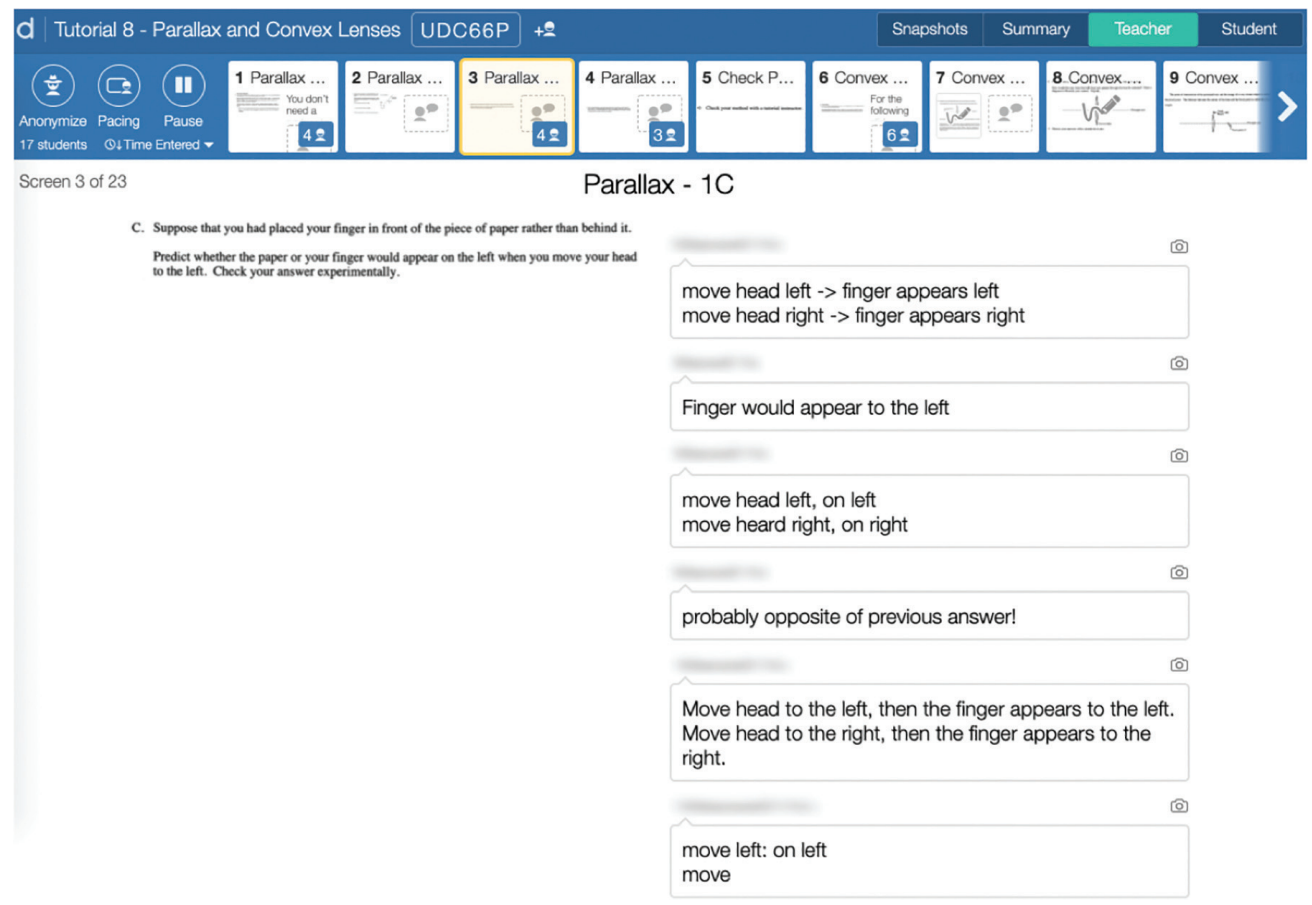

Figura 4: Exemplo de respostas dos alunos a uma questão do tutorial na tela do software Desmos.

magnitude da força elétrica entre um próton e um elétron em um átomo". Tais problemas são em um primeiro momento analisados individualmente pelos membros de cada equipe com o objetivo de elaborarem estratégias de solução. Na sequência, cada equipe discute as estratégias vislumbradas por seus respectivos membros e apresenta uma solução coletiva para o problema. A equipe que primeiro apresentar estimativas coerentes, com resposta na ordem de magnitude mais próxima, é declarada vencedora.

Na modalidade presencial, cada sessão com atividades de estimativa conta com uma lista de cinco ou seis grandezas cujas respectivas ordens de magnitude devem ser determinadas em certas unidades de medida. Os alunos são orientados a pensar individualmente por cinco minutos em estratégias de solução e depois a se reunirem com suas equipes para resolver os problemas. Para auxiliar nas discussões, são disponibilizados quadros brancos móveis. Os estudantes são alertados a não "adivinharem" as respostas, ou simplesmente buscarem na internet, mas sim pensarem numa forma coerente de obtê-las. A consulta a qualquer material que possa fornecer valores básicos é permitida. O tempo total destinado a cada sessão é de 30 min. Quando a equipe termina de resolver todos os problemas, chama o professor para verificar suas respostas. A primeira equipe que estimar corretamente todos os valores é a vencedora.

Há mudanças importantes na versão online das atividades de estimativa. Essas passam a ter uma etapa assíncrona e outra síncrona. Na primeira, os alunos recebem, com dois dias de antecedência, dois problemas abertos e devem trabalhar com suas equipes para resolvê-los. Cada equipe é responsável por: submeter suas respostas no Ambiente Virtual de Aprendizagem adotado (i.e., Canvas ${ }^{9}$ ); e garantir que qualquer um de seus membros seja capaz de apresentar as soluções encontradas. Na segunda etapa (sessão síncrona), dois estudantes da turma são sorteados aleatoriamente para apresentar as soluções de suas respectivas equipes.

Em ambas modalidades de implementação subjazem os princípios de que os alunos podem aprender uns com os outros; que o comprometimento de cada aluno com sua equipe (e vice-versa) favorece o engajamento cognitivo e afetivo nas atividades de ensino; e que atividades de estimativa auxiliam no desenvolvimento de habilidades individuais e coletivas de análise e solução de problemas.

\subsubsection{Atividades de delineamento experimental}

Para a realização dos projetos a serem desenvolvidos na AP50, os alunos precisam fazer medidas experimentais, analisar dados e conduzir simulações computacionais. As Atividades de Delineamento Experimental (ADE) têm como foco auxiliá-los na construção de habilidades associadas, em particular, a tais ações. São distribuídos guias para orientação dos trabalhos que incluem: resultados esperados de aprendizagem; medidas de se-

\footnotetext{
${ }^{9}$ O Canvas (https://www.instructure.com/canvas) é um ambiente virtual de aprendizagem utilizado pela Universidade de Harvard, similar ao Moodle. Nele, os professores desenvolvem e administram páginas referentes as suas disciplinas, nas quais disponibilizam materiais e atividades aos alunos.
} 
gurança; listagem e apresentação dos materiais para a atividade; contextualização do que será realizado; breves explicações sobre possíveis montagens; e uma série de questões a serem respondidas pelas equipes. Ao todo, são realizadas cerca de cinco ADE ao longo do semestre, em sessões de 1h30min cada. Assim como nas Atividades de Estimativa, a participação individual é avaliada pelos demais membros da equipe e pelo professor como um fator na composição do escore associado à dimensão Profissionalismo (vide seção 2.1.4.

No formato presencial, as equipes se reúnem em torno de mesas contendo os materiais necessários para a atividade. Com base nos guias, as equipes se engajam em ações de coleta, análise e interpretação de dados. Por exemplo, em uma atividade experimental intitulada "Pêndulo balístico", os alunos são solicitados a realizarem cálculos, testar seus aparatos e produzir um vídeo para subsequente análise com o software Tracker ${ }^{10}$ As atividades são planejadas de modo que haja triangulação entre aspectos teóricos, experimentais e computacionais, sempre que possível. Segue, a título de ilustração, as orientações iniciais da referida tarefa.

Nesta atividade experimental, sua equipe deve construir um aparato capaz de transformar uma esfera em um projétil. Vocês deverão calcular onde o projétil pousará (no chão) e alocar o alvo exatamente no local previsto. Em seguida, vocês testarão o aparato e verificarão a distância da esfera em relação ao alvo. Vocês deverão gravar um vídeo do projétil e o analisá-lo no software Tracker, a fim de verificar os cálculos realizados.

$\mathrm{Na}$ versão online, as equipes são dispostas em salas particulares em software de comunicação remota (e.g., Zoom) e as atividades práticas são substituídas por vídeos gravados que possibilitam a análise computacional. O professor e/ou os monitores transitam entre as salas para auxiliar os alunos.

Entre os princípios que sustentam as ADE podemos destacar o "aprender fazendo" (hands and head-on); a ideia de que os alunos podem aprender uns com os outros; e de que o desenvolvimento de habilidades experimentais pode ser melhor alcançado com o trabalho colaborativo em equipes.

\subsubsection{Conjunto de problemas - reflexão}

Como apontado anteriormente, a resolução de conjuntos de problemas conta com uma etapa assíncrona, individual, e outra síncrona, coletiva. A ideia é que os estudantes se esforcem para responder da melhor maneira que puderem aos problemas antes das aulas, sem consultar os colegas, e em aula, trabalhem com suas equipes para

10 O Tracker (https://physlets.org/tracker/) é um software gratuito, e Open Source, de modelagem e vídeo análise, voltado especificamente para o Ensino de Física. O software identifica objetos de interesse em vídeos (e.g., uma bola) e rastreia seu movimento, gerando gráficos de posição $\mathrm{x}$ tempo, velocidade $\mathrm{x}$ tempo etc. corrigir suas soluções, dirimir dificuldades conceituais e identificar partes que precisam ser melhor entendidas. Ao final desse tipo de atividade, as equipes entregam suas soluções e reflexões por escrito ao professor.

Os alunos recebem conjuntos com quatro ou cinco problemas, e lhes é concedido o prazo de uma semana para trabalharem sozinhos. Para resolver cada problema, indica-se que os alunos utilizem apenas canetas de tinta preta ou azul e sigam um procedimento de quatro etapas: (i) Introdução: o estudante deve destacar as informações importantes e resumir o problema. Se possível, deve incluir um diagrama e anotar os pressupostos a serem considerados; (ii) Elaborar um plano: o aluno deve dividir o problema em questões menores e gerenciáveis, identificando quais as relações físicas que aplicará; (iii) Executar o plano: o esquema proposto é colocado em prática, explicando cada passo; (iv) Avaliar a solução: o estudante deve verificar a razoabilidade física dos resultados encontrados. A seguir, apresentamos um exemplo de problema utilizado nesta etapa.

Emprego na DuPont! Você e sua equipe foram recentemente contratados para trabalhar como físicos na empresa DuPont, empresa voltada para a agricultura, nutrição, segurança e proteção, materiais de alta performance, tecnologias de cor e revestimento e tecnologias de eletrônicos e comunicação. O chefe da sua equipe pediu para que determinassem onde um ion de cloro de carga negativa - e poderia ficar perto de um íon de dióxido de carbono. $O$ íon de dióxido de carbono é composto por dois íons de oxigênio, cada um com carga-2e e um íon de carbono com carga +3 e. Esses ions estão dispostos em uma linh a com o ion de carbono colocado a meio caminho entre os dois íons de oxigênio. A distância entre cada ion de oxigênio e o íon de carbono é $3 \times 10^{-11} \mathrm{~m}$. Assumindo que o ion de cloro está em uma linha perpendicular ao eixo do dióxido de carbono e que esta linha atravessa o ín de carbono, qual é a distância de equilíbrio para o íon de cloro em relação ao ín de carbono nessa linha? Por razões de simplificação, assumam que o íon de dióxido de carbono não se deforma na presença do íon de cloro.

A resolução de problemas com a técnica proposta auxilia no desenvolvimento de habilidades de resolução de problemas e na autoavaliação do próprio conhecimento e das próprias habilidades (habilidades metacognitivas). Subjacente ao trabalho de reflexão das soluções está o princípio pedagógico que ressignifica o erro como fator importante para a aprendizagem. Seguindo a estratégia proposta, os alunos podem aprender algumas práticas que auxiliam na resolução de problemas, como: planejar a solução; desdobrar um problema complexo em problemas menores; e verificar a solução justificando a sua razoabilidade. Essa última pode incluir a avaliação de: aspectos associados à simetria; casos limitantes e/ou especiais; relações entre a solução encontrada com outras soluções conhecidas; unidades e da ordem de grandeza das respostas.

Durante as sessões síncronas, em torno de cinco sessões 
de 1h30min cada ao longo do semestre, os estudantes trabalham com suas equipes para melhorar e/ou corrigir suas soluções, refletindo sobre o que fizeram e determinando o que precisam revisar. Nessa etapa, os alunos são orientados a utilizar apenas caneta de tinta vermelha, para diferenciar as novas anotações das soluções feitas em casa.

Para estimular a reflexão, o docente solicita aos alunos que respondam às seguintes questões:

1. Descreva o que você aprendeu ao trabalhar neste conjunto de problemas antes de revisá-lo em aula. Você acredita ser capaz de aplicar em um contexto inteiramente novo os conceitos que você explorou nesse conjunto de problemas? Por exemplo, você seria capaz de resolver um problema envolvendo os mesmos conceitos físicos, mas de uma forma que você nunca viu antes?

2. Baseado em sua experiência geral com esse conjunto de problemas, descreva o que você precisa entender melhor.

Passados cerca de 40 minutos de aula, o professor fornece as soluções detalhadas dos problemas para que os alunos possam confirmar suas soluções e fazer quaisquer ajustes que julguem necessário. Por fim, as resoluções, com todos os erros apontados e a maneira de contornálos, bem como as respostas às questões de reflexão, são entregues ao professor. A equipe é responsável por garantir que todos os membros entreguem as soluções completas, e devidamente marcadas, com as respostas às questões de reflexão. Os trabalhos enviados individualmente resultarão em uma pontuação compartilhada com a equipe. Isso significa que os estudantes que não se esforçam na etapa individual, ou não marcam suas soluções corretamente durante a fase em equipe, reduzem não apenas as suas pontuações, mas também as dos seus colegas de equipe. Essa avaliação é feita em termos de esforço e da qualidade da reflexão. Na seção 2.1.4 a avaliação é explicada de forma mais detalhada.

Em uma versão online da AP50 os mesmos procedimentos podem ser viabilizados dividindo as equipes em salas de apoio em um software de comunicação remota (e.g., Zoom) durante o encontro síncrono. Em paralelo, todos os alunos também se conectam em um aplicativo de mensagens instantâneas (e.g., Slack ${ }^{11}$ no qual podem entrar em contato com o professor e o mentor da equipe solicitando auxílio.

\subsubsection{Readiness Assurance Activities}

As Readiness Assurance Activities (RAA) têm como objetivo principal garantir que os estudantes estejam aprendendo os conceitos básicos estudados e desenvolvendo habilidades de resolução de problemas. Em sessões

\footnotetext{
11 O Slack (https://slack.com) é um aplicativo de comunicação instantânea para trabalho colaborativo e compartilhamento de arquivos.
}

síncronas com possibilidade de consulta a materiais e à internet, são apresentados problemas para os alunos resolverem em duas etapas: uma individual, sem interação com os colegas, e outra coletiva, na qual discutem suas soluções com suas respectivas equipes buscando consenso nas respostas. Por meio de algum recurso que permita o recebimento de feedback instantâneo, como cartelas com grade de alternativas (semelhantes a bilhetes de premiação instantânea), ou software especializado, as equipes indicam suas respostas e são informadas se estão ou não corretas. A pontuação máxima é atingida quando a resposta correta é escolhida na primeira tentativa e vai diminuindo até zero, conforme se esgotam as possibilidades de indicação de resposta no instrumento utilizado.

Na AP50, as RAA ocorrem em torno de cinco vezes ao longo do semestre, em sessões de 1h30min. Em cada sessão, 30 min são destinados à etapa individual e $1 \mathrm{~h}$ à etapa em equipe. Usualmente, abrangem uma unidade do livro-texto (dois-três capítulos) e múltiplos conceitos de um mesmo tema são abordados. As questões e problemas apresentados aos alunos são semelhantes aos utilizados em atividades do Peer Instruction, Tutoriais e Conjuntos de Problemas. Os estudantes são avaliados pela correção das respostas e recebem nota tanto pelo desempenho individual (50\%), quanto pelo desempenho em equipe (50\%). Entretanto, essa avaliação não tem como objetivo classificar os estudantes, mas sim estimular o trabalho em equipe e orientá-los no processo de aprendizagem, ajudando-os a identificar lacunas de entendimento dos conceitos. Ademais, esse componente avaliativo é uma pequena parte do sistema de avaliação da disciplina, explicado em maior detalhe na subseção 2.1.4. Na disciplina, as RAA se valem do aplicativo Learning Catalytics, que indica se as respostas, na submissão em equipe, estão corretas ou não (feedback instantâneo). Diferente da alternativa do uso das cartelas, o uso do Learning Catalytics permite aplicar questões de vários tipos, não se limitando às de múltipla escolha.

Caso a equipe julgue que alguma questão está mal formulada, ou que a correção proposta pelo professor não está correta, pode interpor um recurso por escrito, justificando as razões e apresentando evidências para ampará-las. Apenas equipes, não indivíduos, podem apresentar recursos, e somente aqueles bem apresentados e coerentes são considerados na avaliação. Se uma questão estiver com problemas, apenas as equipes que apresentaram recurso terão sua pontuação corrigida. O professor pode julgar o recurso no instante em que ele é apresentado ou em momento posterior. Eles devem trazer argumentos, seguidos de evidências que os suportem, extraídas do próprio livro-texto ou de outra fonte confiável. Quando o recurso é baseado em uma questão que está escrita de forma ambígua, a equipe deve sugerir uma forma de redação que elimine a ambiguidade. 
A possibilidade de recurso faz com que os alunos fiquem atentos e tenham uma postura reflexiva quanto às atividades propostas pelo professor. Além disso, possibilita que revisem os conceitos para elaborarem a argumentação que sustenta o recurso.

Ao tentarem entrar em consenso acerca da resposta, os estudantes aprimoram suas habilidades de trabalho colaborativo e se desenvolvem enquanto equipes. Isso ocorre, principalmente, devido à necessidade de ouvir e confiar nos colegas. Como se trata de uma tarefa avaliativa com aspecto individual e em equipe, o estudante se prepara não apenas visando o próprio desempenho, responsabilizando-se também pela aprendizagem dos colegas. Assim como na atividade de resolução de problemas e reflexão, há na RAA o princípio pedagógico subjacente da valorização do erro. Afinal, o erro instiga a discussão nas equipes, fazendo com que ponderem as razões que as levaram a cometê-lo.

$\mathrm{Na}$ modalidade online da disciplina, as atividades RAA também ocorrem em encontros síncronos com duração de 1h30min com uso de um aplicativo de webconferência (Zoom) e do Learning Catalytics (LC), já usado na modalidade presencial para apresentação das questões e coleta das respostas. Transcorridos $30 \mathrm{~min}$ da disponibilização das questões para a turma, as respostas individuais são registradas e os alunos são divididos em salas de apoio no aplicativo Zoom, uma por equipe, para discutirem os problemas, escolherem suas respostas e receberem feedback pelo LC. O professor e os mentores ficam à disposição das equipes para eventuais esclarecimentos. Caso as equipes apresentem recursos, o professor os avalia posteriormente e informa sobre o resultado em mensagem de e-mail para toda a classe.

\subsubsection{Projetos ao longo do semestre}

A principal atividade da AP50 é o desenvolvimento de projetos que visam transpor o conhecimento dos conceitos construídos pelo estudante para o contexto do mundo real. Como princípio básico, se assume que os alunos devem ter protagonismo em relação à própria aprendizagem e a dos colegas no desenvolvimento dos projetos e de suas atividades suporte. Todas as etapas precedentes têm, entre seus propósitos, a construção dos conhecimentos e habilidades necessárias para que os estudantes sejam capazes de desenvolver, de forma autônoma, e em equipes, projetos vinculados a necessidades reais.

Alan November [21, uma das referências que influenciaram os princípios pedagógicos subjacentes à construção da AP50, destaca que as pessoas têm um desejo intrínseco de aprender, o qual é desestimulado por fatores extrínsecos usualmente valorizados em escolas e universidades, como provas e avaliações calcadas exclusivamente na apreciação do nível de conhecimento dos alunos, punindo-os ou recompensando-os por meio de notas. Ancorado na ideia de motivação intrínseca, oriunda da Teoria da Autodeterminação, de Deci e
Ryan [22], November argumenta que é possível fomentar a motivação discente promovendo propósito, autonomia e domínio do conteúdo. Para isso, na AP50, utiliza-se o desenvolvimento de projetos que envolvam, em algum grau, componentes de empatia e bem social, liberdade criativa e atividades complementares que possibilitem o aprofundamento em conhecimentos de física necessários à construção do projeto. Em um dos projetos os estudantes são orientados a construírem um instrumento musical com materiais recicláveis, inspirado no projeto venezuelano "El Sistema", do maestro José Antonio Abreu, que usa música como meio de transformação social e já fomentou a criação de mais de 150 orquestras jovens na Venezuela.

O desenvolvimento dos projetos é orientado por princípios pedagógicos que sustentam que a aprendizagem ocorre na prática, de forma ativa, que as atividades de ensino devem ter propósito para os alunos, sendo baseadas em problemas reais, e que os estudantes precisam ter certo grau de autonomia no seu processo de aprendizagem. Além disso, as orientações e atividades desenvolvidas ao longo da construção e apresentação dos projetos são propostas a fim de promover condições para que os estudantes desenvolvam uma série de habilidades, que também orientam o aspecto técnico das etapas anteriores da disciplina, a saber: análise qualitativa, análise quantitativa, diagnóstico, design, trabalho em equipe, comunicação, aprendizagem autodirigida, ética e profissionalismo.

Ao longo do semestre, é solicitado aos estudantes que se envolvam em projetos, produzindo, em equipes selecionadas pelo professor, artefatos que utilizem os conhecimentos físicos e habilidades adquiridas ao longo do processo de aprendizagem. Entretanto, o planejamento e a elaboração dos projetos iniciam antes mesmo que as etapas precedentes sejam concluídas. Assim, as próprias demandas de aprendizagem são orientadas pelas necessidades suscitadas no desenvolvimento das propostas. A cada novo projeto, novas equipes são formadas.

Os temas dos projetos, e algumas pré-condições, são propostos pelo professor, mas as equipes têm autonomia para desenvolvê-los da maneira que julgarem mais adequada. Dentre os temas, são selecionados, preferencialmente, aqueles que tenham potencial para instigar o senso de propósito dos estudantes. O docente também orienta que as equipes produzam uma apresentação e um relatório para cada projeto. Em ambas as tarefas, as equipes precisam comunicar, de maneira clara e acurada cientificamente, as etapas de produção e os resultados do projeto.

Como parte da avaliação da disciplina, os estudantes avaliam os colegas de equipe e a si mesmos, destacando a contribuição de cada um para o andamento do projeto ${ }^{12}$ É importante que os estudantes que estão trabalhando e

12 O protocolo original de avaliação entre os colegas de equipe pode ser acessado em: https://if.ufrgs.br/ ives/harvard/ap50/a nnex4.pdf 
contribuindo para a equipe recebam feedbacks positivos; e que aqueles que não estão recebam sugestões para melhorar. Esse sistema de avaliação possibilita que os indivíduos possam aprimorar suas práticas como membros de equipe, tais como: chegar em classe preparado; participar ativamente das atividades; compartilhar suas soluções individuais para as atividades; ouvir e respeitar o ponto de vista dos colegas.

$\mathrm{Na}$ modalidade presencial da disciplina, são desenvolvidos três projetos ao longo do semestre, cada um com duração aproximada de um mês. No caso de projetos que necessitem algum gasto financeiro para a sua construção, as equipes recebem um orçamento fixo para gerenciarem. Em todos os projetos, além de desenvolverem um protótipo, as equipes preparam uma apresentação e um relatório, na forma de um artigo científico, detalhando os procedimentos e resultados. No início de cada projeto, o professor entrega às equipes um documento com instruções e orientações básicas para o seu desenvolvimento (Project Brief) e apresenta o problema a ser enfrentado.

Tomando como exemplo o caso do projeto denominado Symphosium, citado anteriormente, o professor apresenta o projeto social venezuelano El Sistema e expõe aos alunos um pequeno documentário sobre o tema 13 O docente comenta que faltam recursos financeiros para que todos os estudantes tenham instrumentos, e explica que alguns alunos do projeto fazem seus próprios instrumentos com papelão. Infelizmente, esses instrumentos não geram sons. Assim, o problema é introduzido aos alunos da AP50: como produzir um instrumento, utilizando materiais recicláveis, que possa ser utilizado pelas crianças para aprenderem música? Para isso, os conhecimentos de física se tornam necessários para melhorar a qualidade do som dos instrumentos.

No documento entregue aos estudantes, além de ser apresentada a tarefa, que consiste na construção de um instrumento musical funcional feito com materiais recicláveis e na produção de um vídeo de 2 a 4 minutos de duração mostrando o instrumento em funcionamento, também são expostos detalhes para guiar o desenvolvimento do projeto, como, por exemplo, os requisitos do instrumento musical, os aspectos que serão avaliados e os objetivos de aprendizagem.

Em seguida, após a leitura do documento, as equipes são orientadas a redigir uma proposta 14 e um contrato de equipe $15 \mathrm{Na}$ proposta, cada equipe apresenta, em uma página, um modelo de protótipo com uma breve descrição do seu funcionamento, podendo conter imagens e/ou diagramas que auxiliem na explicação. Com isso, o mentor da equipe e o professor podem

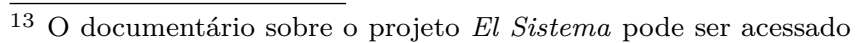
em: https://www.youtube.com/watch?v=yDQ6c_bLr2o

14 Um exemplo de proposta utilizado na AP50 pode ser acessado em: https://if.ufrgs.br/ ives/harvard/ap50/annex5.pdf

15 Orientações para elaboração do contrato de equipe original pode ser acessado em: https://if.ufrgs.br/ ives/harvard/ap50/annex6. pdf
}

orientar o planejamento, caso algo esteja inadequado, antes mesmo que a equipe comece a trabalhar. No contrato de equipe, os estudantes destacam as expectativas da equipe sobre como eles trabalharão juntos, quais serão as responsabilidades de cada membro e o que farão para resolverem eventuais problemas e desacordos. Tendo em vista que os alunos usualmente não estão habituados a trabalharem de forma colaborativa no contexto acadêmico, o contrato facilita a aprendizagem de habilidades relacionadas ao trabalho colaborativo, pois os coloca a pensar ativamente no gerenciamento das tarefas e dos possíveis conflitos. Além disso, diferentemente dos métodos tradicionais de ensino em que os estudantes assumem responsabilidades exclusivamente com o professor, na AP50, por meio do contrato, eles assumem responsabilidades com os colegas. Após a aprovação da proposta e do contrato por parte do mentor (ou do professor), os alunos se engajam na construção do projeto, cujos materiais são disponibilizados pelo docente.

A montagem dos protótipos acontece nas sessões de laboratório (uma vez por semana), nas quais os estudantes têm acesso aos materiais necessários à montagem do projeto. Tendo em vista que o desenvolvimento de projetos não é um processo linear, mas sim iterativo, as equipes são orientadas a utilizarem um caderno de campd ${ }^{16}$ (Engineering Design Notebook) para manterem um histórico do projeto e registrarem pesquisas, observações, ideias, rascunhos, comentários e questões durante o processo. A qualidade e completude das anotações compõem parte da avaliação das equipes.

Ademais, para que aprendam o processo de revisão de suas ações, recomenda-se que os projetos sejam conduzidos de acordo com as etapas especificadas no Engineering Design Process, desenvolvido pela Acreditation Board for Engineering and Technology. Os elementos do processo são os seguintes: (i) Identificar a necessidade ou problema; (ii) pesquisar a necessidade ou problema; (iii) desenvolver possíveis soluções; (iv) selecionar as melhores soluções; (v) construir um protótipo (um modelo); (vi) testar a(s) solução(ões); (vii) comunicar a(s) solução(ões); e (viii) remodelá-las com base nas informações coletadas durante os testes e soluções. Esse processo, que é cíclico e ocorre diversas vezes durante a confecção de um projeto, visa ensinar os alunos a revisarem seu planejamento e suas ações constantemente. Nessa perspectiva, os estudantes são estimulados a pensarem sobre o processo e não sobre o produto final, entendendo e engajando-se em uma situação real de criação. Em oposição aos métodos tradicionais de ensino, nos quais as atividades baseiamse apenas na memorização e, no máximo, aplicação de conceitos, na AP50, os alunos são estimulados ao pensamento criativo.

\footnotetext{
$\overline{16}$ As orientações originais para a construção do caderno de campo podem ser acessadas em: https://if.ufrgs.br/ ives/harvard/ap50 /annex7.pdf
} 
Ao final de um mês, o projeto é apresentado em uma feira pública, na qual os alunos divulgam os processos e resultados e são avaliados por jurados externos. As equipes são questionadas acerca do processo de design descrito anteriormente e dos conceitos físicos envolvidos no projeto. O foco da feira não está no funcionamento ou não do protótipo desenvolvido pelas equipes, mas no conhecimento construído para que chegassem até ele. Novamente, enfatiza-se o processo e não o produto. No exemplo do projeto Symphosium, é solicitado aos estudantes que façam uma breve demonstração do instrumento musical em funcionamento para um grupo de avaliadores externos e que respondam a questões acerca da física envolvida na construção do instrumento. Nesse processo, é incentivado que todos os membros da equipe participem. Por isso, os jurados podem selecionar quem deverá responder aos questionamentos. Uma série de possíveis questionamentos é apresentada aos estudantes antes da feira, para que possam estar preparados. As mesmas perguntas são entregues aos jurados, como ponto de partida para os questionamentos, sem a necessidade de se ater a elas. As questões devem cobrir conceitos como: alcance musical, volume sonoro, timbre, fator de qualidade e estabilidade do instrumento. Como exemplo, em relação ao timbre do instrumento, são apresentadas as seguintes questões: qual o espectro harmônico de seu instrumento? Esse espectro varia com a altura do tom tocado? Você pode explicar qualitativamente a presença ou ausência de harmônicos produzidos por seu instrumento? Que fatores afetam o espectro harmônico, em outras palavras, você pode mudar o timbre conforme toca seu instrumento? Quais alterações no design você fez para influenciar no timbre de seu instrumento?

A última etapa dos projetos é a elaboração de um relatório, ao estilo de um artigo científico, que deve ser entregue uma semana após a feira. No relatório referente ao projeto que estamos exemplificando, as equipes são orientadas a inserir resultados e discussões a respeito das seguintes medidas: (1) alcance musical do instrumento; (2) nível de intensidade sonora a um metro; (3) energia sonora produzida; (4) eficiência energética do instrumento (proporção de energia sonora produzida pela quantidade de energia transferida para o instrumento); (5) espectro harmônico; (6) fator de qualidade; e (7) estabilidade. Após a avaliação dos relatórios, as equipes têm alguns dias para realizar as modificações e correções sugeridas e reenviá-los ao professor.

Outros exemplos de propostas de projetos na AP50 são: InSPECT, focado na construção, calibração e tomada de medidas com um espectrômetro de baixocusto, que possa ser usado, por exemplo, para análise de concentração de substâncias na água potável; Ecotricity, cujo objetivo é o armazenamento de energia elétrica de forma limpa, com o delineamento e a construção de um capacitor de baixo-custo, com a maior taxa de capacitância por massa que os estudantes conseguirem; Crack-a-thon, competição entre os alunos para a construção de um cofre em que apenas a equipe que o projetou consiga abri-lo, ao mesmo tempo que tentarão abrir os cofres uns dos outros. O "cofre" deve ser composto por uma caixa com um mecanismo de fechamento que opere a partir de princípios do eletromagnetismo.

Na AP50 online algumas modificações foram realizadas. A primeira, e mais significativa, é que os alunos não precisam necessariamente construir um artefato físico. As equipes são orientadas a apresentarem um design detalhado, no formato de vídeo ou pôster, com o intuito de convencerem potenciais investidores com bons conhecimentos científicos. A definição do projeto é flexibilizada, ficando a cargo das equipes decidirem o tema que melhor se adeque as suas condições, desde que seja uma aplicação dos conceitos físicos estudados. Uma vez que os estudantes não precisam mais construir um aparato físico, o número de conceitos que deve estar presente no design é maior do que na versão presencial. O caderno de campo físico é substituído por um documento online compartilhado pelos membros da equipe. Por fim, as feiras são realizadas via aplicativo de webconferência (i.e., Zoom), no qual cada equipe tem uma sala particular e os jurados transitam entre as salas para fazerem a avaliação.

O objetivo do vídeo ou pôster é que os alunos apresentem ao "investidor" todas as etapas do design, explicando: (i) qual problema o produto busca solucionar; (ii) como o produto funciona e como ele resolve o problema; (iii) quais conceitos estão incorporados no design e por que eles são importantes para o funcionamento do produto. Além disso, as equipes são estimuladas a utilizarem recursos visuais para explicar como o produto funciona.

\subsubsection{Avaliação geral}

Um dos principais diferenciais da forma como o processo avaliativo é conduzido na AP50, em relação a abordagens tradicionais de ensino em disciplinas introdutórias de Física, é seu caráter formativo. Não há exames parciais ou finais para definição do conceito do aluno na disciplina. Outros critérios além da correção das respostas são usados para esse fim. O conceito final é determinado pela avaliação em todas as atividades desenvolvidas durante todo o semestre considerando os seguintes domínios: Aprendizagem Autodirigida; Aprendizagem do Conteúdo; Trabalho em Equipe; e Profissionalismo.

Os estudantes se engajam em uma aprendizagem autodirigida ao identificarem e atenderem as suas próprias necessidades educacionais, conhecendo suas atuais capacidades, dominando o uso de fontes de informação, planejando e solucionando problemas. No domínio referente à aprendizagem autodirigida, destacam-se como parte da avaliação as anotações realizadas no livro-texto na etapa de preparação prévia e as soluções e reflexões feitas nas resoluções de problemas. 
Na AP50, o conteúdo é orientado em função daquilo que é necessário para os estudantes desenvolverem, da melhor maneira possível, os projetos. Assim, o domínio do conteúdo é demonstrado pelos estudantes na medida em que alcançam os objetivos de aprendizagem especificados no documento de orientação dos projetos (Project Briefs). Isso ocorre, principalmente, por meio da aplicação dos conhecimentos físicos na resolução de problemas e na coleta, análise e interpretação de dados. Essa dimensão é avaliada através dos RAAs e dos relatórios dos projeto ${ }^{17}$ com os respectivos cadernos de campo 18

O trabalho em equipe é outra dimensão central na AP50, pois se entende que aquilo que é produzido por uma equipe é potencialmente melhor do que aquilo que é realizado pela soma de esforços individuais. Equipes são capazes de resolver problemas que seriam impossíveis para qualquer indivíduo. Por isso, as habilidades voltadas ao trabalho colaborativo são cada vez mais essenciais para a vida profissional. A fim de desenvolver tais habilidades e avaliar o desenvolvimento das equipes ao longo do semestre, são consideradas as apresentações ${ }^{19}$ que as equipes fazem referentes aos projetos e as avaliações entre os colegas de equipe, que contam também com análises do próprio desempenho.

Por fim, o profissionalismo no contexto da disciplina se caracteriza pela demonstração de respeito de cada aluno com seus colegas, professores e monitores; pela pontualidade e participação nas atividades propostas na disciplina; pela tomada de decisões, e execução de ações consideradas socialmente justas e honestas. Nesse sentido, os componentes avaliativos da dimensão profissionalismo são: participação, pontualidade e ética.

No Quadro 1. apresentamos os componentes avaliativos que contribuem para a avaliação de cada dimensão e os critérios considerados em cada um deles.

$\mathrm{Na}$ AP50, todas as atividades são avaliadas em uma escala geral de quatro pontos (de 0 a 3 ), representada da seguinte maneira: $0=$ insuficiente; $1=$ necessita de melhoraria; 2 = atende às expectativas; e $3=$ excede significativamente às expectativas (dado apenas nos casos mais excepcionais). Recomenda-se que para cada componente avaliativo haja um protocolo de avaliação correspondente, orientado pelos critérios apresentados no Quadro 1. Assim, os alunos ficam cientes acerca daquilo que se espera que eles atinjam em cada atividade. Além disso, contribui para que se concentrem em todas as dimensões consideradas importantes na disciplina, não focando apenas no entendimento do conteúdo. Nas notas

\footnotetext{
17 Um dos protocolos utilizados na AP50 para a avaliação dos relatórios dos projetos pode ser acessado em: https://if.ufrgs.br/ $\sim$ ives/harvard/ap50/annex8.pdf

io $\mathrm{O}$ protocolo original de avaliação dos cadernos de campo pode ser acessado em: https://if.ufrgs.br/ ives/harvard/ap50/annex9. pdf

19 Um dos protocolos utilizados na AP50 para a avaliação das apresentações das equipes nas feiras pode ser acessado em: https: //if.ufrgs.br/ ives/harvard/ap50/annex10.pdf
}

de rodapé do presente artigo, que apontam para os arquivos de anexo 1 a 4 e 8 a 10, apresentamos exemplos de protocolos de avaliação utilizados na disciplina.

Alguns critérios apresentados no Quadro 1 contam com uma estrutura interna, na qual uma série de elementos compõem a avaliação total. Além disso, a escala geral de quatro pontos é adaptada às especificidades dos critérios. Por exemplo, os relatórios das equipes são avaliados em dois parâmetros: conteúdo e forma. O primeiro é analisado por meio do resumo, dos requisitos solicitados (veja exemplo dos requisitos solicitados no projeto Symphosium na seção 2.1.3), da precisão científica e da contribuição dos membros da equipe; o segundo é avaliado em termos da organização do texto, do uso apropriado de gráficos, citações e notações, da pontualidade e da extensão do relatório. A equipe atende às expectativas (nota 2) quanto ao resumo quando o apresenta de forma completa e concisa, cobrindo todos os pontos abordados no artigo e utilizando menos de 150 palavras. Se, pelo contrário, a equipe omitir um ou dois pontos, ou escrever entre 150 e 200 palavras, ela recebe 1 ponto. Por fim, a equipe recebe 0 (zero) nesse quesito caso o resumo exceda 200 palavras ou quando nenhum resumo é apresentado. Nesse caso específico, não há pontuação 3. No entanto, em termos de requisitos, por exemplo, a equipe recebe 3 pontos caso o relatório apresente medidas que excedam as solicitadas; 2 pontos caso todos os requisitos estejam presentes e os dados apresentados sejam plausíveis; 1 ponto quando um ou dois componentes não estão expostos explicitamente ou os dados não são plausíveis; e 0 (zero) se deixar de abordar mais de dois componentes exigidos.

Mesmo com diferentes estruturas internas, relacionadas aos critérios específicos, para cada dimensão é estabelecida uma pontuação final, na escala de quatro pontos (3-0), sendo a nota definida pela atividade em que o aluno obteve a menor pontuação, pois entendese que todas as atividades são igualmente importantes. Na Figura 5 é apresentada a forma que as pontuações nos domínios são convertidas em um conceito final na disciplina.

Como pode ser observado, o processo avaliativo como um todo, e em sua estrutura mais específica, foi delineado para a formação discente e não como ferramenta classificatória. Trata-se não somente de uma mudança em técnicas de avaliação, mas sim de uma quebra paradigmática em relação a como o processo de avaliação em disciplinas introdutórias de Física costuma ser concebido.

\section{Considerações Finais}

Ao longo da discussão da proposta metodológica que embasa a disciplina AP50, procuramos destacar princípios subjacentes aos métodos e metodologias empregadas. Cabe voltar ao ponto de partida e explicitar um princípio que norteia a própria formulação da disciplina e que, 
Quadro 1: Critérios de avaliação e contribuição dos componentes avaliativos nas quatro dimensões: aprendizagem autodirigida, domínio do conteúdo, trabalho em equipe e profissionalismo.

\begin{tabular}{|c|c|c|}
\hline Dimensão & Componentes avaliativos & Critérios \\
\hline \multirow[t]{2}{*}{$\begin{array}{l}\text { Aprendizagem } \\
\text { autodirigida }\end{array}$} & $\begin{array}{l}\text { 1. Anotações no livro-texto: nas anotações realizadas } \\
\text { pelos alunos no livro-texto, verifica-se em que medida os } \\
\text { comentários dos estudantes refletem uma aprendizagem } \\
\text { autodirigida. }\end{array}$ & $\begin{array}{l}\text { Qualidade, quantidade, pontualidade } \\
\text { e distribuição }\end{array}$ \\
\hline & $\begin{array}{l}\text { 2. Conjuntos de problemas: a partir das soluções dos } \\
\text { problemas e das reflexões apresentadas pelos estudantes, } \\
\text { afere-se sua habilidade de resolver problemas, analisar seu } \\
\text { próprio trabalho e determinar o que precisa ser revisado } \\
\text { para uma melhor compreensão do conteúdo. }\end{array}$ & Esforço e reflexão \\
\hline \multirow[t]{2}{*}{$\begin{array}{l}\text { Domínio do } \\
\text { conteúdo }\end{array}$} & $\begin{array}{l}\text { 1. Readiness Assurance Activities: ao final de cada } \\
\text { unidade de estudo do livro-texto, os estudantes são } \\
\text { avaliados quanto às suas habilidades em resolver entre } 8 \text { e } \\
11 \text { problemas, primeiramente de forma individual e depois } \\
\text { em colaboração com suas equipes. }\end{array}$ & Número de acertos \\
\hline & $\begin{array}{l}\text { 2. Relatórios dos projetos: ao término dos projetos, as } \\
\text { equipes submetem à avaliação um relatório, nos moldes de } \\
\text { um artigo científico, e um caderno de campo, utilizado ao } \\
\text { longo do processo para registrar todas as etapas do projeto. }\end{array}$ & Conteúdo e forma \\
\hline \multirow[t]{2}{*}{ Trabalho em equipe } & $\begin{array}{l}\text { 1. Apresentações dos projetos: Após o desenvolvimento } \\
\text { dos projetos, as equipes são avaliadas por um grupo de } \\
\text { monitores da disciplina e um conjunto de jurados externos } \\
\text { em uma feira de apresentação dos projetos. }\end{array}$ & $\begin{array}{l}\text { Atendimento aos requisitos do } \\
\text { projeto, apresentação dos resultados } \\
\text { e habilidade dos integrantes de } \\
\text { explicarem a Física envolvida no } \\
\text { trabalho e de discutirem tais } \\
\text { elementos }\end{array}$ \\
\hline & $\begin{array}{l}\text { 2. Avaliações entre os colegas: para cada projeto, os } \\
\text { estudantes avaliam a sua própria contribuição e as dos } \\
\text { colegas de equipe para o andamento do trabalho. Também } \\
\text { analisam a postura de cada indivíduo como membro da } \\
\text { equipe. }\end{array}$ & $\begin{array}{l}\text { Participação nas atividades, } \\
\text { preparação para as aulas, } \\
\text { comunicação clara e respeitosa, } \\
\text { presença e pontualidade, } \\
\text { responsabilidade e flexibilidade para } \\
\text { lidar com conflitos e discordâncias }\end{array}$ \\
\hline \multirow[t]{3}{*}{ Profissionalismo } & $\begin{array}{l}\text { 1. Participação: a participação dos estudantes é avaliada } \\
\text { nas seções de Peer Instruction (registradas no acesso ao } \\
\text { Learning Catalytics), na avaliação realizada pelos colegas } \\
\text { de equipe e pelos mentores, os quais analisam, } \\
\text { principalmente, aquelas atividades que não são pontuadas } \\
\text { em outras dimensões. }\end{array}$ & Nível de engajamento nas atividades \\
\hline & $\begin{array}{l}\text { 2. Pontualidade: os estudantes são avaliados quanto à } \\
\text { sua pontualidade nas atividades programadas no calendário } \\
\text { da disciplina pelos colegas de equipe e pelo mentor. }\end{array}$ & $\begin{array}{l}\text { Pontualidade nas aulas e nas } \\
\text { entregas de trabalhos }\end{array}$ \\
\hline & $\begin{array}{l}\text { 3. Ética: ao longo de todo o semestre, os estudantes são } \\
\text { avaliados quanto a sua conduta em todas as atividades. } \\
\text { Analisa-se se elas estão de acordo com padrões éticos } \\
\text { aceitos socialmente. }\end{array}$ & $\begin{array}{l}\text { Respeito, honestidade e } \\
\text { comportamento justo e igualitário } \\
\text { com os outros }\end{array}$ \\
\hline
\end{tabular}

após o detalhamento apresentado da metodologia, pode ser melhor apreciado pelo leitor: disciplinas de Física Geral podem oferecer oportunidades de aprendizagem mais diversificadas, e com mais sentido para os alunos, se também pensadas na perspectiva "física aplicada". É comum disciplinas introdutórias de física terem caráter eminentemente teórico, com a presença de atividades experimentais, em maior ou menor parte, para corroborar o que está sendo mostrado. Parte-se da discussão de conceitos e equações, seguida pela ilustração da aplicabilidade de tais elementos em situações escolhidas para evidenciar suas potencialidades. Esta lógica pode ser invertida, senão em toda a disciplina, pelo menos em alguns módulos, ao trazer para primeiro plano situaçõesproblema que potencialmente interessem aos alunos. A partir disso os conteúdos são introduzidos para auxiliar na construção de respostas, na medida que se fazem necessários. Esse cenário, iniciado pela necessidade de aplicação do conhecimento, e não pela obrigação de estudar o conteúdo em si, é profícuo para o estabelecimento de metodologias de aprendizagem baseadas em projetos. Estudar física a partir de situações-problema e desafios, considerando aspectos de relevância social e econômica quando oportunos, pode ser viabilizado com o desenvolvimento de projetos colaborativos. Entre outros aspectos, esse tipo de abordagem pode também auxiliar 


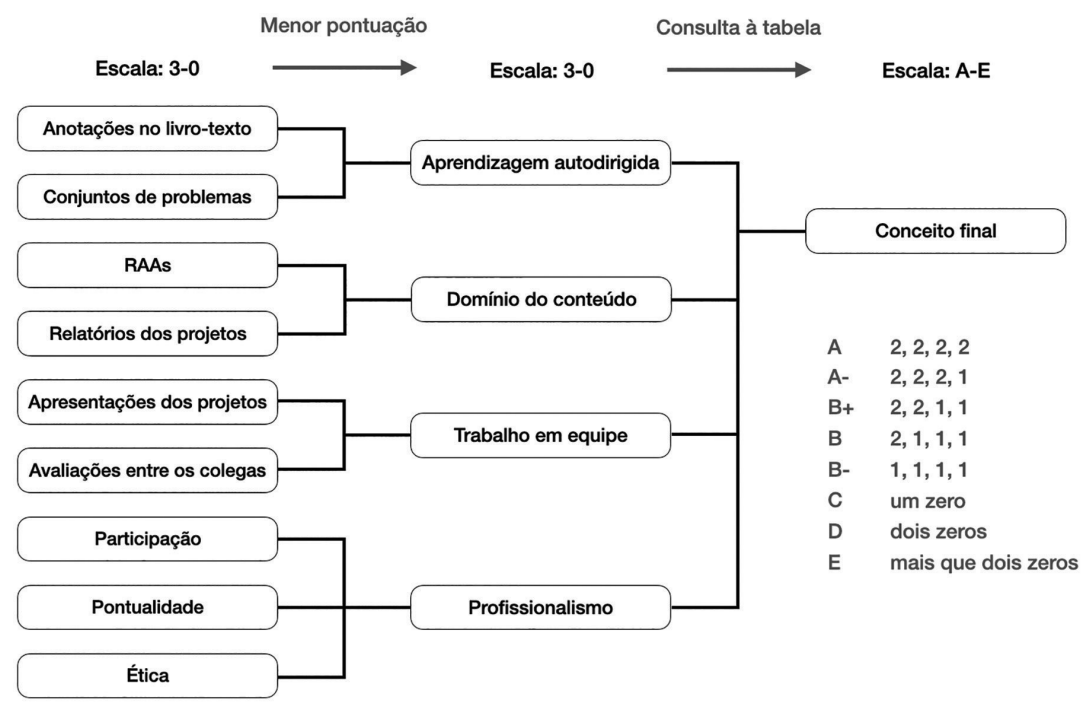

Figura 5: Conversão da pontuação dos domínios avaliativos em um conceito final da disciplina.

a equilibrar possíveis desmotivações associadas ao estudo do "conhecimento pelo conhecimento" em fases iniciais dos cursos de formação.

Sem sombra de dúvidas, o contexto em que a proposta aqui apresentada foi desenvolvida é um espaço privilegiado. Nem todas instituições de ensino conseguem disponibilizar suporte material e humano similar ao oferecido pela Universidade de Harvard como apoio às suas disciplinas. O que também não quer dizer que, mesmo nessa instituição, não houve resistência para implementar as inovações didáticas em pauta. Por exemplo, a aceitação de mudanças no escopo das atividades avaliativas, passando a incluir dimensões como trabalho colaborativo e profissionalismo, foi vista com ceticismo pelo corpo docente. Foram necessárias ações de comunicação e divulgação interna sobre o trabalho desenvolvido e os resultados alcançados pela disciplina, na forma de seminários e convites para visitas às aulas, para que certas desconfianças fossem desfeitas. Reações como essa são de se esperar, em particular para cursos de Engenharia e Bacharelado em Física no Brasil cujo foco avaliativo das disciplinas de Física costuma se restringir ao desempenho alcançado pelos estudantes na resolução de problemas. Para que inovações didáticas mais ousadas, como a que apresentamos sejam adotadas (e mantidas ao longo do tempo), é fundamental a elaboração de estratégias institucionais de apoio que permitam dar visibilidade ao que é feito e, gradualmente, diminuam a insegurança trazida pelo novo.

Para efetivamente reformular o ensino introdutório de física em outras instituições se faz imprescindível a consideração dos respectivos contextos locais e a realização de um exercício de transposição, sobretudo, metodológica 20 Que soluções alternativas, e criativas,

\footnotetext{
20 Considerações mais detalhadas sobre a adoção de métodos ativos no contexto brasileiro, tais como Team-Based Learning e
}

podem ser usadas para adequar as atividades de ensino às possibilidades locais específicas? Como seguir os princípios subjacentes a essas atividades de ensino, sem descaracterizar suas finalidades com a modificação, acréscimo ou subtração dos métodos e ferramentas apresentados? A resposta a essas e outras questões de mesma natureza não são únicas e tampouco definitivas.

Ao apresentarmos como a proposta metodológica está sendo implementada na Universidade de Harvard, nossa intenção não é a mostrar uma receita, ou gabarito, sobre como deve ser feita no Brasil ou demais países, mas sim indicar que outras perspectivas e metas para o ensino de Física podem ser almejadas. Conforme destacamos na introdução, trata-se da construção e evolução de uma inovação didática, e esta pode se transformar tanto para o enriquecimento de práticas quanto para a simplificação de atividades didáticas com o passar do tempo. Assim, é de se esperar que versões futuras da metodologia associada à AP50 variem em relação ao que foi aqui apresentado. Entendemos que as reflexões e caminhos apontados permanecerão relevantes.

A implementação de atividades de ensino inovadoras que aumentem as chances de os estudantes darem mais significado para os assuntos em pauta é algo que vale todos os esforços, mesmo que a implementação se dê de forma parcial (porém coerente). Algumas vezes, criase a expectativa de que qualquer inovação só deva ser adotada caso forneça solução completa para todos os problemas levantados. Contudo, avanços parciais e imperfeitos ainda são melhores do que avanço algum, e a própria manutenção de soluções existentes pode se dar mais em função da familiaridade que se tem com elas do que pelos resultados que apresenta, conforme apontamos na Introdução.

o Peer Instruction, presentes na metodologia da AP50, podem ser encontrados em [15, 23, 27. 
A título de conclusão, enfatizamos nossa posição em defesa da importância que aspectos pedagógicos, e de ampliação dos horizontes sobre o que cabe ensinar, guiem a busca e adoção de inovações didáticas. A redução da necessidade de transformação metodológica do ensino à tarefa de procurar por novas técnicas e ferramentas tecnológicas é um erro que pode e deve ser evitado, se ao menos estivermos atentos a ele.

\section{Agradecimentos}

Ives Solano Araujo agradece ao $\mathrm{CNPq}$ pela bolsa de Produtividade em Pesquisa.

\section{Referências}

[1] M. Prince, J. Eng. Educ. 93, 223 (2004).

[2] S. Freeman, S.L. Eddy, M. McDonough, M.K. Smith, N. Okoroafor, H. Jordt e M.P. Wenderoth, Proc. Natl. Acad. Sci. U. S. A. 111, 8410 (2014).

[3] P. Fairfield, Education After Dewey (Continuum, New York, 2009), $1^{\mathrm{a}}$ ed.

[4] P.C. Blumenfeld, E. Soloway, R.W. Marx, J.S. Krajcik, M. Guzdial e A. Palincsar, Educ. Psychol. 26, 369 (1991).

[5] L.K. Michaelson, A.B. Knight e L.D. Fink, TeamBased Learning: A Transformative Use of Small Groups (Greenwood, Westport, 2002).

[6] J. Bergman e A. Sams, Flip Your Classroom (International Society for Technology in Education, Washington, 2012).

[7] S.D. Chesters, The Socratic Classroom: Reflective Thinking through Collaborative Inquiry (Sense, Rotterdam, 2012).

[8] M. Knoll, J. Ind. Teach. Educ. 34, 59 (1997).

[9] J. Dewey, The School and Society (Revised) (The University of Chicago Press, Chicago, 1899).

[10] J. Dewey, Experience and Education (Kappa Delta Pi, New York, 1938).

[11] W.H. Kilpatrick, The Project Method: The use of the purposeful act in the educative process. (Teachers College-Columbia University, New York, 1918).

[12] A. Quintana-Nedelcos e J. Llovera-González, LatinAmerican J. Phys. Educ. 3, 19 (2009).

[13] F. Cambi, História Da Pedagogia (Editora Unesp, São Paulo, 1999), $2^{\mathrm{a}}$ ed.

[14] E. Mazur, Peer Instruction: A User's Manual (Prentice Hall, Upper Saddle River, 1997).

[15] I.S. Araujo e E. Mazur, Cad. Bras. Ensino Física 30, 362 (2013).

[16] C. Henderson e M.H. Dancy, Phys. Rev. Spec. Top. Phys. Educ. Res. 5, 020107 (2009).

[17] D. Hestenes, M. Wells e G. Swackhamer, Phys. Teach. 30, 141 (1992).

[18] L. Ding, R. Chabay, B. Sherwood e R. Beichner, Phys. Rev. Spec. Top. - Phys. Educ. Res. 2, 1 (2006).

[19] E. Mazur, Principles \& Practice of Physics (Pearson, London, 2014).

[20] L.C. McDermott e P.S. Shaffer, Tutorials in Introductory Physics (Prentice Hall, Upper Saddle River, 2002).
[21] A. November, Who Owns the Learning? Preparing Students for Success in the Digital Age (Solution Tree Press, Bloomington, 2012).

[22] E.L. Deci e R.M. Ryan, Intrinsic Motivation and SelfDetermination in Human Behavior (Plennum Press, New York, 1985).

[23] T. Espinosa, I.S. Araujo e E.A. Veit, Física Na Esc. 14, 4 (2016).

[24] T. Espinosa, I.S. Araujo e E.A. Veit, Cad. Bras. Ensino Física 33, 962 (2016).

[25] M.G. Müller, I.S. Araujo, E.A. Veit e J. Schell, Rev. Bras. Ensino Física 39, e3403 (2017).

[26] T. Espinosa, I. Araujo e E. Veit, Rev. Bras. Ensino Ciência E Tecnol. 12, 69 (2019).

[27] T. Espinosa, I.S. Araujo e E.A. Veit, Amaz. Rev. Educ. Em Ciências e Matemáticas 16, 5 (2020). 